\title{
Random Motion on Simple Graphs: Addendum
}

\section{G. Papanicolaou}

Received: 15 June 2012 / Accepted: 29 June 2012 /

Published online: 15 July 2012

(C) Springer Science+Business Media, LLC 2012

Regarding our paper "Random motion on simple graphs", Methodology and Computing in Applied Probability, Volume 14, Number 2 (2012), 285-297, DOI: 10.1007/s11009-010-9203-x (joint work with E. Papageorgiou and D. Lepipas), we would like to communicate that we have recently become aware of some earlier works of profesor Marc Yor et al.

In one of those works (Barlow et al. 1989) (Theorem 3, p. 303) a complete answer has been given(!), actually in a much more general setup, to the "Open Problem" mentioned at the end of our paper.

In another work (Yor 1997) (Chapter 17, Section 2, in particular in Exercise 17.4, p.113) the author establishes (with proofs) most of the results of Section 2 of our paper, regarding exit times.

\section{References}

Barlow MT, Pitman JW, Yor M (1989) Une extension multidimensionnelle de la loi de l'arc sinus. Sém. Prob. XXIII. In: Lect notes in math, vol 1372. Springer, Berlin, Heidelberg, New York, pp 294-314

Yor M (1997) Some aspects of Brownian motion—part II: some Martingale problems. Birkhauser

V. G. Papanicolaou $(\bowtie)$

Department of Mathematics, National Technical University of Athens, Athens, Greece

e-mail: papanico@math.ntua.gr 